\title{
DECISIONS
}

\section{A 25-year-old woman with diabetes in custody}

\author{
Fiona G. Kouyoumdjian MD PhD, Wendy Lai MD, Aaron Orkin MD MSc, Barbora Pek MD
}

\begin{abstract}
A 25-year-old woman who is handcuffed was brought to the emergency department in the custody of police officers. She has type 1 diabetes and last took her insulin over a day ago. She is slurring her words and appears fatigued. She asks if her sugar can be checked. The officers request that she be treated and stabilized before she is taken to the local correctional facility. They expect the patient to remain in detention for several days and ask if her urine can be checked for drugs.
\end{abstract}

\section{Does the patient have to remain in handcuffs?}

Concerns regarding privacy, confidentiality and legal consequences may prevent a patient in custody from discussing relevant aspects of medical history in the presence of security staff. Physical restraints, such as handcuffs, may cause physical and emotional discomfort, obstruct the physical examination and undermine the patient's trust and confidence in the physician's professional independence. ${ }^{1}$ This is particularly important because there are high rates of morbidity and mortality across a variety of health status indicators in patients who experience detention and incarceration. ${ }^{2,3}$ Health care encounters can be an affirmative opportunity to enhance health in this population, and a recent systematic review showed that health care interventions can improve the health of this population while in custody and at the time of release. ${ }^{4}$

It is reasonable for physicians to request accommodations to facilitate an assessment, such as asking security staff to leave the room, stand on the other side of a curtain or barrier, or remove restraints during an examination. Police officers and correctional authorities have the authority to decide whether to remove restraints or to leave the patient, and may make this decision in consideration of the risk of danger or flight by the patient.

Are the patient's charges or convictions a part of history-taking?

This information is usually not pertinent to patient care in any clinical setting, but there are exceptions such as a forensic psychiatric assessment. A recent observational study in the United States found that knowledge of criminal history may lead to discrimination by health care workers. ${ }^{5}$ In the absence of clinical relevance and with the risk of bias in mind, it is not necessary to ask this patient for details of criminal involvement as part of the routine history.

\section{What clinical information can be shared with the police officers?}

A physician's ethical obligations regarding confidentiality, including legislated exceptions, ${ }^{6}$ are not contingent on legal status and therefore extend to persons in custody. ${ }^{7}$

It may be clinically useful for physicians to obtain collateral history from police or correctional officers. ${ }^{7}$ Physicians should not disclose information about the patient's clinical status or management to security staff, except for the patient's disposition (e.g., whether the patient requires admission to hospital) and any information that would be considered essential while the patient is in their custody. ${ }^{8}$ In Ontario, for example, essential information is limited to information that could eliminate or reduce "a significant risk of serious bodily harm to a person [including the patient] or group of persons."

\section{Should the patient's urine be tested for drugs at the officers' request?}

In specific situations (e.g., when a person is suspected of having operated a vehicle under the influence of drugs or alcohol within the previous $3 \mathrm{hr}$ ), police and correctional officers in Canada are authorized to ask physicians to obtain samples, such as blood or urine, for investigation. ${ }^{9}$ Treating physicians are not obligated to comply with such police requests and should only comply with the patient's consent. ${ }^{10}$ Therefore, for this patient, as with any other, the physician should only test her urine for illicit drugs if clinically indicated, and if the patient consents to the test.

International guidelines for physicians treating patients who are detained or imprisoned specify
Competing interests: None declared.

This article has been peer reviewed.

The clinical scenario is fictional.

Correspondence to: Fiona Kouyoumdjian, KouyoumdjiaF@smh.ca

CMAJ 2016. DOI:10.1503 /cmaj.151232 
that, regardless of known or suspected charges or convictions, physicians "shall not countenance, condone or participate in ... forms of cruel, inhuman or degrading procedures," 11 such as examinations or procedures for the purposes of a criminal investigation. ${ }^{12}$ Further, the physician "must have complete clinical independence in deciding upon the care of a person for whom he or she is medically responsible."11

\section{How should continuity of care be assured at the time of discharge for this patient?}

When the patient is ready for discharge, the physician should outline the requirements for follow-up at the correctional facility, including access to glucose testing equipment, insulin and health care staff. Consistent with practice standards for discharge, ${ }^{6}$ this may include calling the health care staff at the correctional facility to discuss the patient's clinical status and need for follow-up. Depending on the complexity and urgency of the information to be shared, this communication may be done by fax or by sending information in a sealed envelope that is addressed to the health care staff at the correctional facility and either given to the patient or security staff accompanying her.

Health care staff at correctional facilities are licensed health care professionals, and it is appropriate to share relevant clinical information with them for continuity of care unless the patient expressly withdraws or withholds consent to the disclosure of this information. ${ }^{13}$

\section{Case revisited}

Based on the physician's request, the police agreed to remove the handcuffs and leave the room. The police were told that it would take several hours to complete the patient assessment and that the physician would update them about the patient's disposition when possible. The physician took a history and performed a physical examination, guided by the patient's request to have her glucose checked, her history of type 1 diabetes and statement that she had not taken insulin for more than a day. The patient reported that she injected oxycodone several times the previous day and her drug use made it hard for her to manage her diabetes.

The physician determined that the patient was capable of providing informed consent and ordered laboratory investigations. These tests showed that the patient was in diabetic ketoacidosis and appropriate treatment was started.

The physician explained to the officers that there was no clinical indication for drug screening, and the test would not be ordered. The physician also updated the officers about the anticipated length of the patient's stay in hospital, but did not discuss the patient's drug use or other aspects of the patient's assessment and management with them.

The following morning, the patient was ready to be discharged. The physician contacted the health care staff at the correctional facility to discuss the treatment plan and provided the patient with written discharge instructions to share with them. The physician explained to the patient that her care had been discussed with health care staff at the facility and then reviewed symptoms that she should report to the police officers or correctional staff. The physician also recommended that the patient meet with health care staff at the facilty to discuss the management of her diabetes and her drug use.

\section{References}

1. International Dual Loyalty Working Group. Dual loyalty and human rights in health professional practice: proposed guidelines and institutional mechanisms. New York and Cape Town (South Africa): Physicians for Human Rights and the School of Public Health and Primary Health Care, University of Cape Town, Health Sciences Faculty; 2002. Available: https://s3 amazonaws.com/PHR_Reports/dualloyalties-2002-report.pdf (accessed 2016 Jan. 10).

2. Fazel S, Baillargeon J. The health of prisoners. Lancet 2011; 377:956-65.

3. Kouyoumdjian F, Schuler A, Hwang SW, et al. The health status of prisoners in Canada: a narrative review. Can Fam Physician 2016;62:215-22.

4. Kouyoumdjian FG, McIsaac KE, Liauw J, et al. A systematic review of randomized controlled trials of interventions to improve the health of persons during imprisonment and in the year after release. Am J Public Health 2015;105:e13-33.

5. Frank JW, Wang EA, Nunez-Smith M, et al. Discrimination based on criminal record and healthcare utilization among men recently released from prison: a descriptive study. Health Justice 2014;2:6.

6. Physician interactions with police. Ottawa: The Canadian Medical Protective Association; 2011. Available: https://www.cmpa-acpm. ca/duties-and-responsibilities/-/asset_publisher/bFaUiyQG069N/ content/physician-interactions-with-police (accessed 2015 May 1).

7. Nolan B, Ackery A. Collaborating with police in the emergency department while maintaining patient confidentiality: How can we improve? CJEM 2015; 17:437-42.

8. Personal Health Information Protection Act, 2004, S.O. 2004, c. 3 , Sched. A. Toronto: Service Ontario; 2015. Available: www.ontario. ca/laws/statute/04p03 (accessed 2015 Dec. 18).

9. Criminal Code. (R.S.C., 1985, c. C-46). Ottawa: Department of Justice Canada; 2015. Available: laws-lois.justice.gc.ca/eng/ acts/C-46/FullText.html (accessed 2015 Dec. 18).

10. Medico-legal handbook for physicians in Canada. Ottawa: The Canadian Medical Protective Association; 2010. Available: https://www.cmpa-acpm.ca/documents/10179/24981/com_16_ MLH_for_physicians-e.pdf (accessed 2015 Dec. 18).

11. WMA Declaration of Tokyo - Guidelines for physicians concerning torture and other cruel, inhuman, or degrading treatment or punishment in relation to detention or imprisonment. Ferney-Voltaire (France): World Medical Association; 1975. Available: www.wma. net/en/30publications/10policies/c18/ (accessed 2015 Dec. 18).

12. Curran WJ. Ethical and legal problems in medical participation in criminal investigations. N Engl J Med 1976;294:764-5.

13. Circle of care: sharing personal health information for healthcare purposes. Toronto: Information and Privacy Commissioner of Ontario; 2015. Available https://www.ipc.on.ca/images/ Resources/circle-of-care.pdf (accessed 2015 Dec. 18).

Affiliations: Centre for Research on Inner City Health (Kouyoumdjian), St. Michael's Hospital; Department of Emergency Medicine (Lai), Humber River Hospital; Dalla Lana School of Public Health (Orkin), University of Toronto, Toronto, Ont.; Division of Emergency Medicine, Department of Family Medicine (Pek), McMaster University, Hamilton, Ont.

Contributors: All of the authors contributed to the conception and design of the article, drafted it, revised it critically for intellectual content, approved the final version submitted for publication and agreed to act as guarantors of the work. 